\title{
Omalizumab treatment downregulates dendritic cell FceRI expression
}

\author{
Calman Prussin, MD, a Daniel T. Griffith, MD,b Kevin M. Boesel, MD,b \\ Henry Lin, MD, ${ }^{\mathbf{b}}$ Barbara Foster, MS, a and Thomas B. Casale, MD ${ }^{\mathbf{b}}$ Bethesda, Md, and \\ Omaha, Neb
}

\begin{abstract}
Background: Dendritic cells (DCs) are potent antigen-presenting cells that express FceRI, the high-affinity IgE receptor. Although the downregulation of basophil FceRI during antiIgE therapy with omalizumab is well documented, its effect on FeERI expression by DCs has not been reported. Objective: We hypothesized that IgE regulates surface FecRI expression by DCs in vivo and that, consequently, anti-IgE therapy decreases $F c \varepsilon R I$ expression by DCs.

Methods: In a randomized, double-blind, placebo-controlled clinical trial 24 subjects (16 receiving omalizumab and 8 receiving placebo) with seasonal allergic rhinitis received the study drug on days 0 and 28. Serial blood samples drawn on days 0 , $7,14,28$, and 42 were analyzed for precursor DC1 (pDC1) and pDC2 surface expression of Fc $\varepsilon$ RI $\alpha$ by using flow cytometry. Results: Omalizumab caused a significant decrease in surface FceRI expression at all time points examined in both the pDC1 and pDC2 subsets. No significant change was seen with placebo. The maximum decrease in FceRI expression in the omalizumab group was $52 \%$ and $83 \%$, respectively, for the pDC1 and pDC2 subsets. The decrease in Fe\&RI expression by both pDC subsets correlated with the decrease in serum-free IgE and was of a similar magnitude to that found in basophils. A 10-fold decrease in IgE corresponded to a $42 \%$ and $54 \%$ decrease in surface $\mathrm{Fe} \varepsilon \mathrm{RI}$ expression by the pDC1 and pDC2 subsets, respectively.

Conclusion: These results demonstrate that anti-IgE therapy causes a rapid decrease in DC surface FceRI expression and establish that IgE is an important regulator of FceRI expression by DCs. (J Allergy Clin Immunol 2003;112:1147-54.)
\end{abstract}

Key words: Dendritic cells, IgE, anti-IgE, FcERI, omalizumab, antigen-presenting cells

FceRI, the high-affinity IgE receptor, and allergenspecific IgE play an essential role in immediate-type hypersensitivity and allergic disease. ${ }^{1}$ In addition to FceRI expression by the classic cellular mediators of immediate hypersensitivity, in human subjects, antigenpresenting cells (APCs), such as dendritic cells (DCs) and monocytes, express FceRI, and this expression is

From athe Laboratory of Allergic Diseases, National Institute of Allergy and Infectious Diseases, National Institutes of Health, Bethesda, and ${ }^{b}$ the Division of Allergy/Immunology, Department of Medicine, Creighton University, Omaha.

The clinical trial was supported by a grant from Genentech Inc, South San Francisco, Calif. The dendritic cells analyses were funded by the National Institute of Allergy and Infectious Diseases Division of Intramural Research.

Received for publication August 26, 2003; revised September 22, 2003; accepted for publication October 2, 2003

Reprint requests: Calman Prussin, MD, Building 10, Room 11C205, National Institutes of Health, Bethesda, MD 20892-1881.

doi:10.1016/j.jaci.2003.10.003

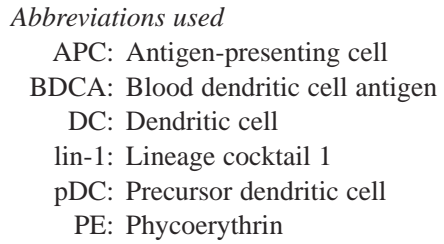

increased in some atopic conditions. ${ }^{2}$ DC expression of FceRI enhances the presentation of allergen to $\mathrm{T}$ cells through an antigen-focusing mechanism, in which FceRI-bound IgE on APCs preferentially captures allergen. ${ }^{3}$ Thus, because of the critical role DCs play in the initiation and $\mathrm{T}_{\mathrm{H}} 2$ polarization of allergen-specific immune responses, ${ }^{4}$ FceRI expression by DCs might have important immunologic and clinical consequences. ${ }^{2}$

DCs are potent APCs that play a critical role in shaping the adaptive immune response to antigens. A number of phenotypic and functional DC subsets have been identified. 5 The 2 most abundant and well-described DC subsets, termed DC1 and DC2, demonstrate unique toll-like receptor repertoires and cytokine expression ${ }^{6}$ and promote $\mathrm{T}_{\mathrm{H}} 1$ and $\mathrm{T}_{\mathrm{H}} 2$ responses, respectively. ${ }^{7,8}$ Although the relationship of these DC subpopulations is undoubtedly more complicated than a 1:1 correlation with the $\mathrm{T}_{\mathrm{H}} 1$ and $\mathrm{T}_{\mathrm{H}} 2$ subsets, they provide a useful starting point to address DC heterogeneity. Precursor DCs (pDCs) are an earlier DC developmental stage that is present in the peripheral blood. In response to an immunologic stimulus, pDCs traffic into tissue and differentiate into mature DCs.

Omalizumab is a humanized therapeutic $\mathrm{mAb}$ against human IgE that effectively reduces free IgE levels by 10- to 100 -fold and is an effective treatment for allergic asthma and seasonal allergic rhinitis. ${ }^{9,10}$ The major immunologic consequence of this decrease in free $\mathrm{IgE}$ is a corresponding decrease in surface FceRI expression by peripheral blood basophils. ${ }^{11,12}$ We thus hypothesized that omalizumab therapy would similarly decrease FceRI expression by DCs. To test this hypothesis, during a clinical trial of omalizumab, we performed a substudy examining the effect of anti-IgE therapy on FceRI $\alpha$ expression by the $\mathrm{pDC} 1$ and $\mathrm{pDC} 2$ subsets. In this report we demonstrate that omalizumab therapy causes a rapid decrease in surface FceRI expression by both the pDC1 and pDC2 subsets. These results further define the role of IgE in the regulation of FcERI expression by DCs and suggest that anti-IgE therapy might have immunomodulatory effects in addition to its inhibition of IgE-mediated hypersensitivity. 


\section{METHODS Study design}

This analysis was performed as a substudy within a single-center, randomized, double-blind, placebo-controlled clinical trial of 24 subjects (16 receiving omalizumab and 8 receiving placebo) with ragweed-induced seasonal allergic rhinitis conducted from December 2001 to March 2002. Subjects 19 to 50 years old with a minimum 2year history of ragweed-induced seasonal allergic rhinitis and a serum IgE level of less than $700 \mathrm{IU} / \mathrm{mL}$ were enrolled. Subjects with a history of asthma or who were currently using corticosteroids, antihistamines, or leukotriene antagonist medications were excluded from the study. Allergy was confirmed with a positive skin test wheal of $5 \mathrm{~mm}$ or larger to mixed giant-short-western ragweed (Hollister-Stier, Spokane, Wash). Subjects were randomly assigned to receive either omalizumab $\left(0.016 \mathrm{mg} \cdot \mathrm{kg}^{-1} \cdot \mathrm{IU}^{-1} \cdot \mathrm{mL}^{-1} \mathrm{IgE}\right)$ or placebo on days 0 and 28. At the completion of the trial, the data were analyzed in a blinded fashion. FceRI $\alpha$ expression on blood pDC cells was determined by means of flow cytometry on day 0 (baseline) and on days $7,14,28$, and 42 . IgE was measured on day 0 (baseline) and on days 3,28 , and 42. The clinical trial and collection of PBMCs were performed at Creighton University, and the DC flow cytometric analyses were performed at the National Institutes of Health. Nasal allergen challenge yielding a $30 \%$ decrease in nasal volume was performed at baseline, and subjects were then challenged with the same dose biweekly during the study. The clinical protocol was approved by the Creighton University Institutional Review Board, and the DC analyses were reviewed by the National Institutes of Health Office of Human Subjects Protection. Each patient provided written informed consent before enrollment in the study.

\section{Free and total IgE concentrations}

Total serum IgE concentration was measured at baseline, and free serum IgE levels were measured on days 3, 28, and 42 . Total IgE levels were measured by using the Immulite 2000 chemiluminescent immunoassay. Human free $\mathrm{IgE}$ (not complexed to omalizumab) was measured by Genentech with a solid-phase ELISA, as previously described. ${ }^{13}$

\section{Preparation of PBMCs}

PBMCs were isolated from EDTA-anticoagulated blood by using 1.083 Ficoll-Diatrizoate density gradient separation and washed twice in PBS. PBMCs $\left(20 \times 10^{6}\right)$ were fixed in $3 \mathrm{~mL}$ of $4 \%$ paraformaldehyde for 5 minutes, washed once in PBS with $0.1 \%$ BSA (PBS-BSA), and then resuspended in PBS $/ 10 \%$ dimethyl sulfoxide (Sigma, St Louis, Mo) and stored at $-80^{\circ} \mathrm{C}$ until analysis. ${ }^{14}$

\section{Antibodies}

Anti-CD2 (clone LT2) FITC and CD19 FITC (clone FMC63; Serotech, Raleigh, NC); HLA-DR, HLA-DP, and HLA-DQ FITC (cloneTU39), HLA-DR phycoerythrin (PE)/Cy5 (clone G46-6), CD4 APC (clone RPA-T4), CD11c APC (clone B-ly6), and CD123 PE (clone 7G3; BD-PharMingen, San Diego, Calif); CD14 PE/Cy5 (clone Tuk4) and CD19 PE (clone SJ25-C1; Caltag, Burlingame, Calif); CD14 FITC (Beckman-Coulter, Fullerton, Calif); CD16 FITC (clone B-E16, BioSource, Camarillo, Calif); blood dendritic cell antigen (BDCA) 2 APC, CD1c biotin (clone BDCA-1; Miltenyi Biotec, Auburn, Calif); goat anti-mouse IgG1 Alexa 647, streptavidin APC (Molecular Probes, Inc, Eugene, Ore); and lineage cocktail 1 (lin-1) FITC (anti-CD3, CD14, CD16, CD19, CD20, and CD56; BD Biosciences, San Jose, Calif) were obtained commercially. The basophil granule-specific mAb 2D7 was a gift from $\mathrm{Dr}$ Lawrence Schwartz (Virginia Commonwealth University). pDC2 cell analyses were performed by using unlabeled anti-FceRI $\alpha$ (clone 22E7, gift from Dr Wayne Levin, Roche) and indirect immunostaining. We were unable to obtain additional 22E7 mAb to complete this work, and thus the $\mathrm{pDC} 1$ staining was performed with PE-labeled anti-FceRI $\alpha$ clone AER-37 (eBioscience, San Diego, Calif). Each $\mathrm{mAb}$ recognizes both free and IgE-bound FceRI $\alpha$. In pilot studies these $2 \mathrm{mAb}$ clones appeared to recognize similar or identical epitopes; both mAbs efficiently blocked binding of the other, and neither mAb was blocked by $\operatorname{IgE}$ competition (data not shown).

\section{Antibody staining and flow cytometry}

Cryopreserved samples were collected, processed as above, and archived at Creighton University. On conclusion of the clinical trial, samples were shipped to the National Institutes of Health for analysis. DC2 and basophil analyses were performed first by using the 22E7 mAb. All DC2-basophil samples from a given donor were processed on the same day to minimize intrasubject variation. After these studies were completed, the DC1 analyses were performed with the AER-37 mAb; all DC1 samples from a given donor were processed on the same day. The analyses and conclusions contained within are not based on direct comparison of DC1 and DC2 fluorescence intensity data and thus are not affected by this change in $\mathrm{mAb}$. Cell-surface FceRI staining was performed with a nonpermeabilizing adaptation of previously described procedures. ${ }^{14,15}$ All buffers were used at $4^{\circ} \mathrm{C}$. Cryopreserved fixed cells were thawed, washed in PBS-BSA, and then blocked in PBS-1\% BSA-5\% nonfat milk powder (PBS-BSA-milk) for 1 hour on ice before mAb staining. For analysis of pDC1 cells, samples were stained in PBS-BSA-milk with lin-1 FITC, CD1c biotin, CD11c PE/Cy5, and anti-FceRI $\alpha$ PE (clone AER-37); washed twice in PBS-BSA; stained with streptavidin APC; washed twice; and analyzed. $\mathrm{pDC} 1$ cells were identified by first gating on $\mathrm{CD}_{1} \mathrm{c}^{+}$, lin-1- cells (Fig 1,F) and back-gating on cells of the corresponding scatter, which were then further gated on CD11c (Fig 1, G). For analysis of pDC2 cells and basophils, cells were incubated with an exclusion panel of FITC-labeled mAbs to CD2, CD16, CD19, HLA-DR, HLA-DP, and HLA-DQ, anti-CD123 $\mathrm{PE}$, anti-CD14 PE/Cy5 (all non-IgG1 isotype), and anti-FceRI (clone 22E7, mouse IgG1 isotype) in PBS/BSA/milk. Cells were then washed twice and incubated with goat anti-mouse IgG1 Alexa 647 in PBS-BSA-milk, washed twice, and analyzed. DC2 were identified as a distinct cluster of CD123 bright cells that stained positive with the exclusion panel and negative for CD14 (Fig 1,A). Basophils were identified as a distinct cluster of CD123 bright cells that stained negative with the exclusion panel and negative for CD14 (Fig 1, A). After gating on the above cell subsets, the mean fluorescence intensity of FcERI was determined (Fig 2).

Data were acquired with a 2-laser, 4-parameter FACS Calibur flow cytometer (BD Biosciences) and analyzed on Cellquest (BD Biosciences) and FlowJo (Tree Star, San Carlos, Calif) software. Typically 300,000 to 600,000 total events were acquired to obtain 1000 or more $\mathrm{pDCs}$ for analysis.

\section{Statistical analysis}

Paired data in Fig 3 were analyzed by using the Wilcoxon signedrank test. Correlative data in Figs 4 and 5 were analyzed by using the Spearman rank correlation test. For correlations for each subject, all IgE and FceRI determinations on study drug were averaged with like results, and a single representative percentage fraction during treatment with the study drug relative to the day 0 baseline value was determined. A single subject receiving omalizumab with outlying pDC2 staining (300\% of baseline) was excluded for linear regression calculations in Figs 4, B; 5, A; and 5, $C$. This subject was included in all correlation calculations and plotted data. Statistical calculations and linear regression analysis were performed with Prism software (GraphPad Software, San Diego, Calif). 


\section{RESULTS \\ Clinical study}

A clinical trial examining the pharmacodynamics of omalizumab therapy was performed from December 2001 through March 2002 in subjects with ragweed-induced seasonal allergic rhinitis and is described in detail elsewhere. ${ }^{16}$ Serial blood samples for IgE levels and flow cytometry were analyzed as detailed in the "Methods" section. The median baseline serum IgE level was 250 and $131 \mathrm{ng} / \mathrm{mL}$ for the omalizumab and placebo groups, respectively. In the omalizumab group free serum IgE decreased $95 \%$ by day 3 of the study, and this decrease was sustained and statistically significant at all time points studied (90\% and $93 \%$ for median decrease on days 28 and 42, respectively).

\section{Identification of pDC subsets in peripheral blood}

During the above-noted clinical pharmacodynamics study, we examined basophil FceRI expression. ${ }^{16}$ During this analysis, we noted a second distinct population and postulated these were cells of the pDC2 subset. This identity was suggested by their characteristic bright staining for CD123 and an exclusion panel consisting of CD2, CD16, CD19, HLA-DR, HLA-DP, and HLA-DQ (Fig 1, $A)$. The DC2 identity of this population was confirmed in pilot experiments on the basis of their uniform positive staining for HLA-DR, BDCA-2, CD4, and FceRI $\alpha$ and negative staining for the basophil-specific granule marker 2D7 (Fig 1, $B-E, \mathrm{n}=4$ subjects; Fig 2, $C$ and $D$ ). In contrast, the basophil population stained negative for HLADR, BDCA-2, and CD4 and positive for 2D7. We then identified cells of the pDC1 subset on the basis of their positive staining for CD1c and CD11c and negative staining for the lin-1 panel (Fig 1, $F$ and $G$ ). ${ }^{17}$ The identity of these pDC1-subset cells was confirmed in pilot experiments on the basis of their uniform positive staining for HLA-DR (data not shown) and FceRI $\alpha$ (Fig 2, $A$ and $B$ ). These results demonstrate that the staining strategy used specifically identifies pDC1 and pDC2.

\section{Effect of omalizumab on pDC surface FceRI expression}

Omalizumab treatment caused a decrease in FceRI $\alpha$ expression by both pDC1 and pDC2 (Fig 2, $A-D$ ). In both subsets the decrease in FceRI expression was apparent by 7 days and was maximal at 28 and 14 days, respectively, for $\mathrm{pDC} 1$ and $\mathrm{pDC} 2$ (Fig 3 and Fig 2, E and $G$ ). The median decrease in surface FceRI expression at these time points was $54 \%$ and $75 \%$, respective1y. In contrast, in the placebo group the maximal decrease for any single time point was $3 \%$ and $20 \%$ for pDC1 and pDC2, respectively.

Relative to the day 0 baseline value, omalizumab caused a significant decrease in FceRI expression by both pDC1 and pDC2 at all time points examined (Fig 3). In contrast, none of the placebo time points showed any significant changes. After omalizumab treatment, the maximum decrease in median FceRI expression was
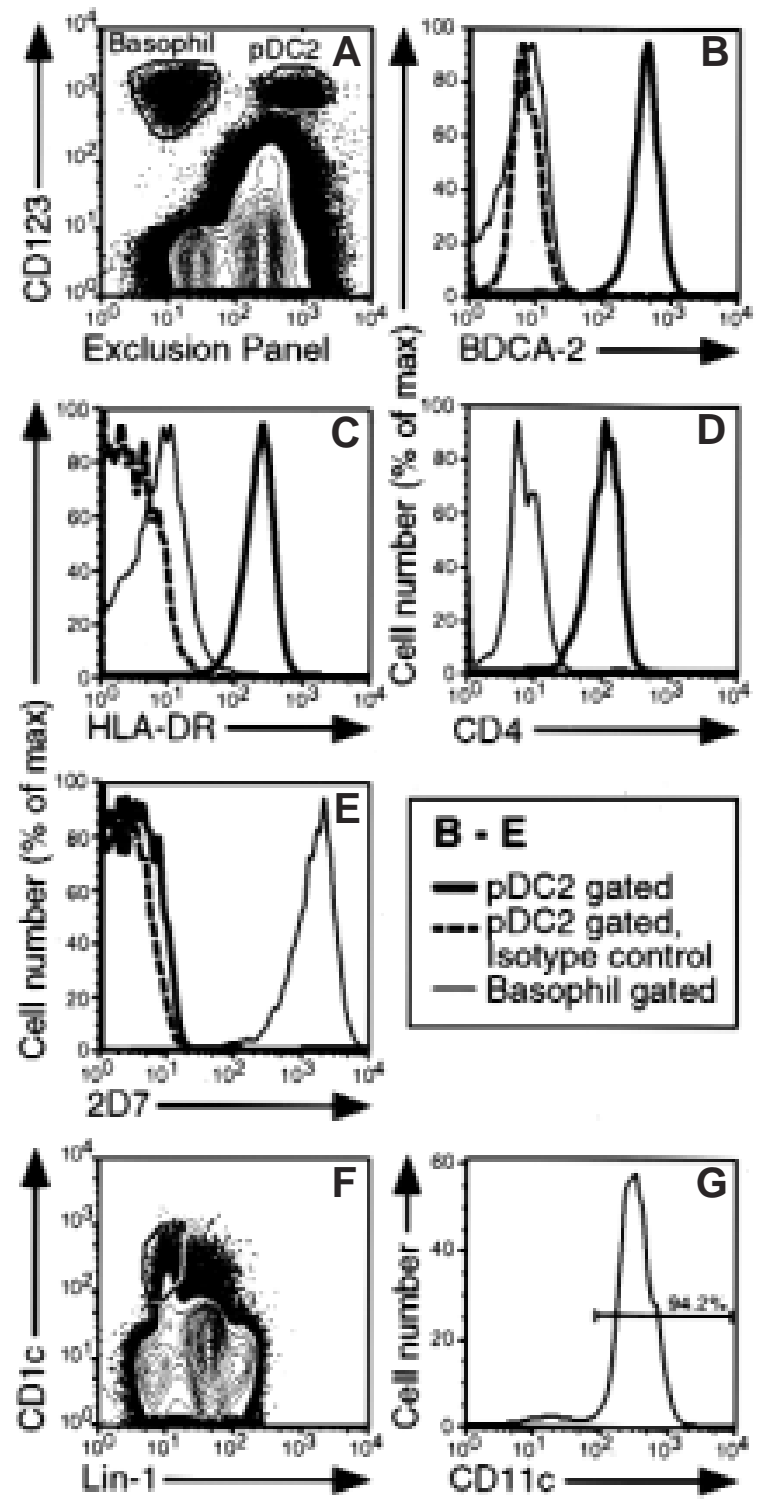

FIG 1. Identification of peripheral blood pDC subsets. A, PBMCs were stained with an mAb to CD123 and an exclusion panel (CD2, CD16, CD19, HLA-DR, HLA-DP, and HLA-DQ), and cells of the pDC2 subset and basophils were identified. After gating on either cells of the pDC2 subset (heavy line) or basophils (light line), the expression of BDCA-2 (B), HLA-DR (C), CD4 (D), and 2D7 (E) was determined ( $n=4$ subjects). The $p D C 1$ subset was identified as a population staining negative for the lin-1 mAb cocktail and positive for CD1c (F) and CD11c (G).

$52 \%$ and $83 \%$, respectively, for the $\mathrm{pDC} 1$ and $\mathrm{pDC} 2$ subsets. These results demonstrate that omalizumab therapy causes a rapid and persistent decrease in surface FceRI expression in cells of both the $\mathrm{pDC} 1$ and $\mathrm{pDC} 2$ subsets.

\section{Correlation of $\mathbf{F c \varepsilon R I}$ expression to serum $\lg \mathrm{E}$}

Although the FceRI response to omalizumab was generally substantial, in Fig 2 we observed a variable response between subjects. One explanation is that in 

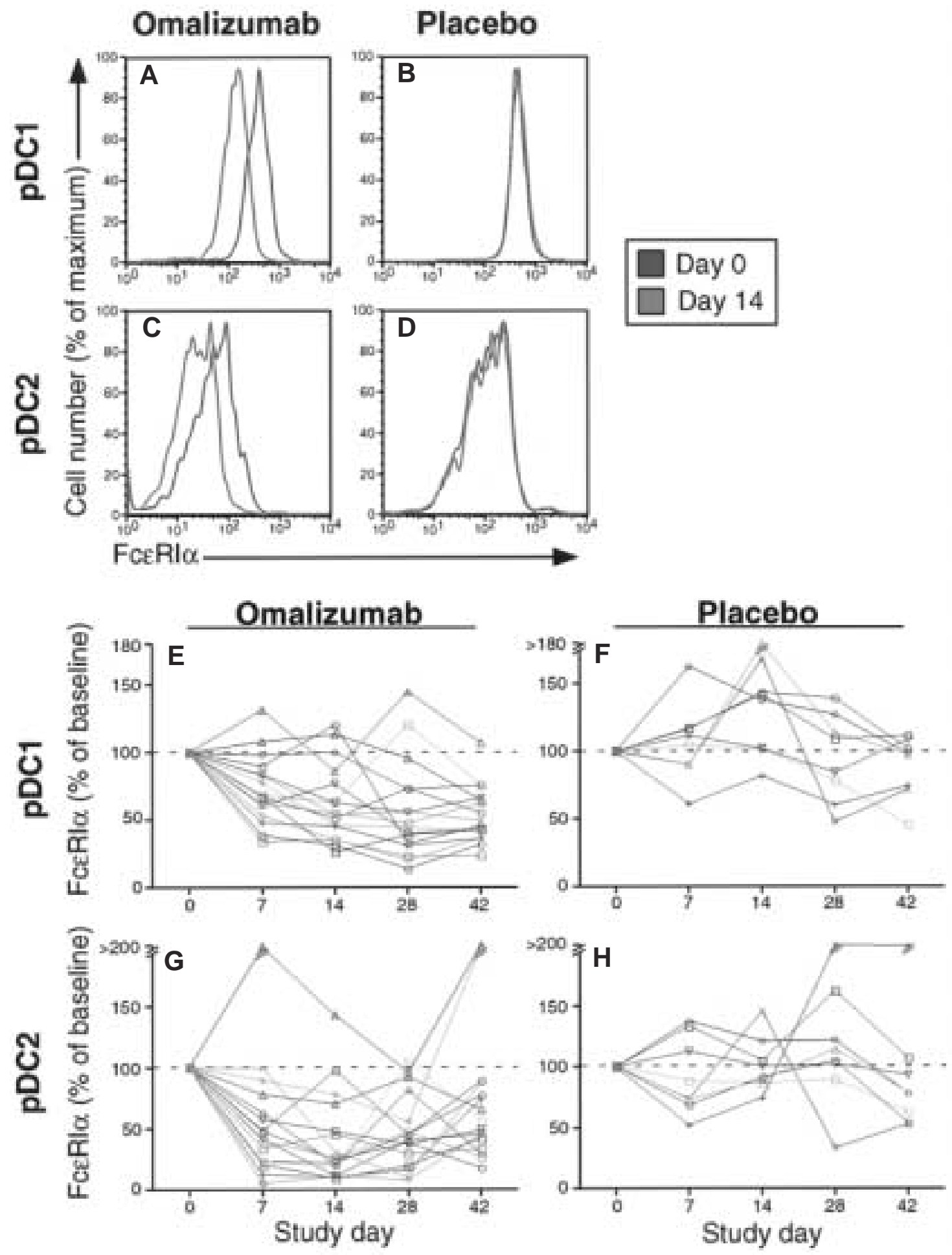

FIG 2. Omalizumab downregulation of FceRl $\alpha$ expression in the $\mathrm{pDC} 1$ and $\mathrm{pDC} 2$ subsets. A-D, After gating on either pDC1 (A and $\mathbf{B}$ ) or pDC2 (C and $\mathbf{D})$ subsets, representative FceRl staining from days 0 and 14 are shown for both an omalizumab-treated ( $\mathbf{A}$ and $\mathbf{C}$ ) and placebo-treated (B and $\mathbf{D})$ subject. For each subject, FceRI expression was normalized to the day 0 baseline value and plotted for each study visit (E-H).

poorly responsive subjects, factors other than IgE might have a greater influence on FceRI expression. Alternatively, it might simply be due to inconsistent reduction of IgE levels in these poorly responding subjects. To deter- mine which of these models explains the variable response to omalizumab, we correlated the change in surface FceRI expression with the change in serum IgE. For both the pDC1 and pDC2 subsets, the change in FceRI 

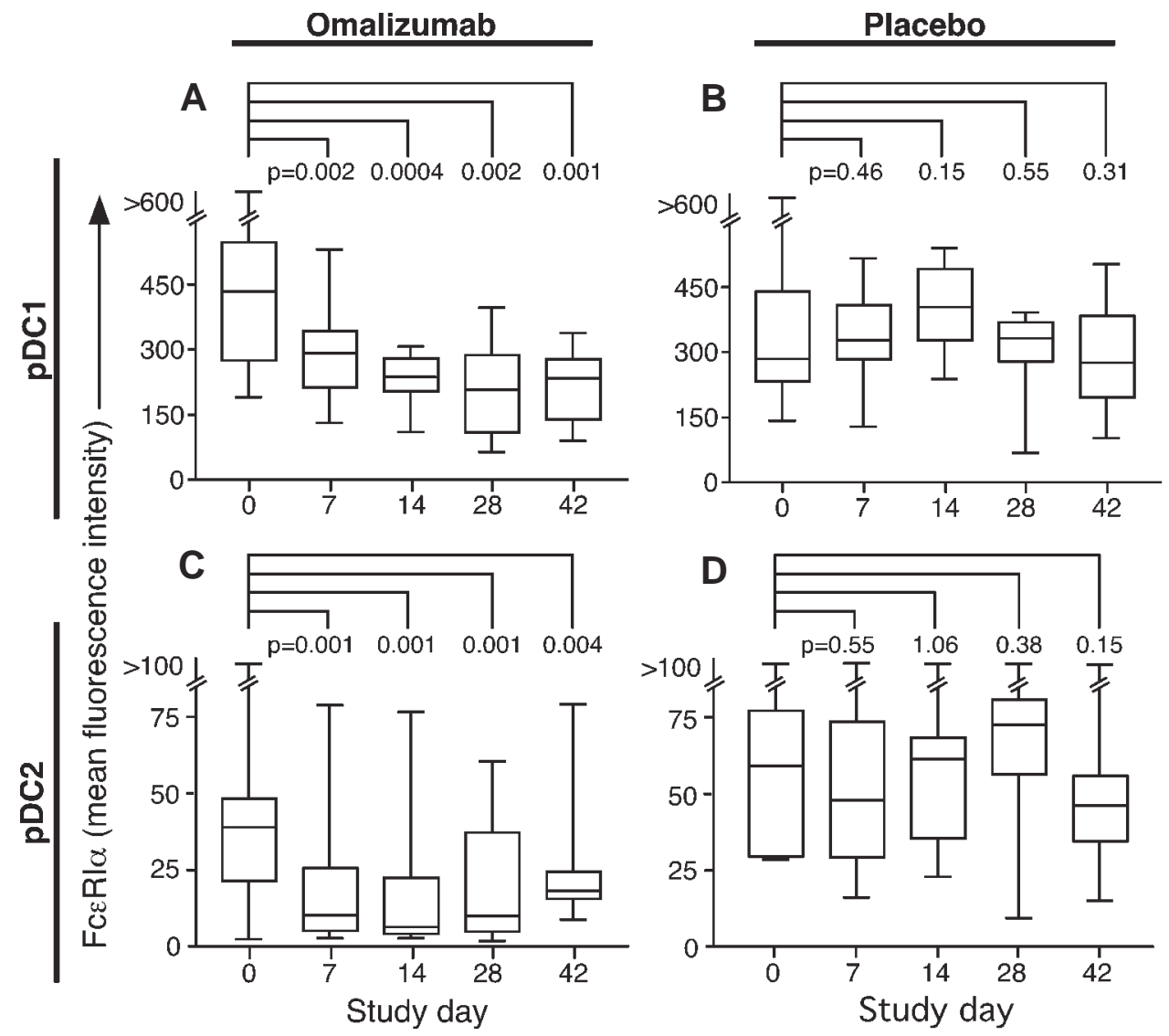

FIG 3. Omalizumab downregulation of FceRl $\alpha$ expression in the pDC1 and pDC2 subsets. A-D, Box-and-whisker plots showing $\mathrm{Fc \varepsilon RI}$ mean fluorescence intensity in pDCs plotted for each study visit. The horizontal middle line represents the median, the top and bottom lines represent the quartile values, and the $T$ bars represent the maximum and minimal values. Statistical significance was determined by using the Wilcoxon signed-rank test.

expression was highly correlated with the change in free IgE (Fig 4). Linear regression analysis yields lines indicating that a 10 -fold decrease in free $\operatorname{IgE}$ resulted in a $42 \%$ and $54 \%$ decrease in FceRI expression by pDC1 and $\mathrm{pDC} 2$, respectively. Linear regression analysis of the basophil results indicates that a 10-fold decrease in IgE resulted in a $63 \%$ decrease in basophil FceRI (data not shown). These results demonstrate that omalizumabinduced surface FceRI downregulation is proportional to the reduction in free $\mathrm{IgE}$.

Although omalizumab decreased FceRI expression in all 3 cell subsets, we sought to determine whether, in a given subject, the reduction observed in one subset was mirrored in the others. To address this question, we correlated the change in FceRI expression between the pDC1, pDC2, and basophil subsets. In each case changes in FceRI expression in a given subset were highly correlated with changes in the other subsets (Fig 5). Linear regression analysis yielded curves with slopes close to 1, indicating that, in a given subject, the magnitude of change in FceRI expression for all 3 subsets was similar. These data demonstrate that in subjects responding to anti-IgE thera- py, downregulation of FceRI expression occurs in parallel among the pDC1, pDC2, and basophil subsets.

\section{DISCUSSION}

In this work we examined FceRI $\alpha$ expression during a clinical trial of omalizumab and demonstrate that omalizumab treatment is associated with a decrease in cellsurface FceRI expression in both the pDC1 and pDC2 subsets. Furthermore, we found a correlation between the decrease in DC FceRI expression and the decrease in $\operatorname{IgE}$ in this study population. These results are consistent with the conclusion that this decrease in FceRI expression occurs as a direct consequence of the reduction in free $\mathrm{IgE}$ concentration by omalizumab.

Omalizumab is a humanized $\mathrm{mAb}$ that has therapeutic activity in asthma and allergic rhinitis. ${ }^{9,10}$ By binding IgE, omalizumab reduces free $\operatorname{IgE}$ and, consequently, the expression of FceRI by basophils ${ }^{11,12}$ and, presumably, mast cells. The major known clinical consequence of these reductions is the inhibition of immediate hypersensitivity. In Figs 2 and 3 we present the novel finding that omal- 

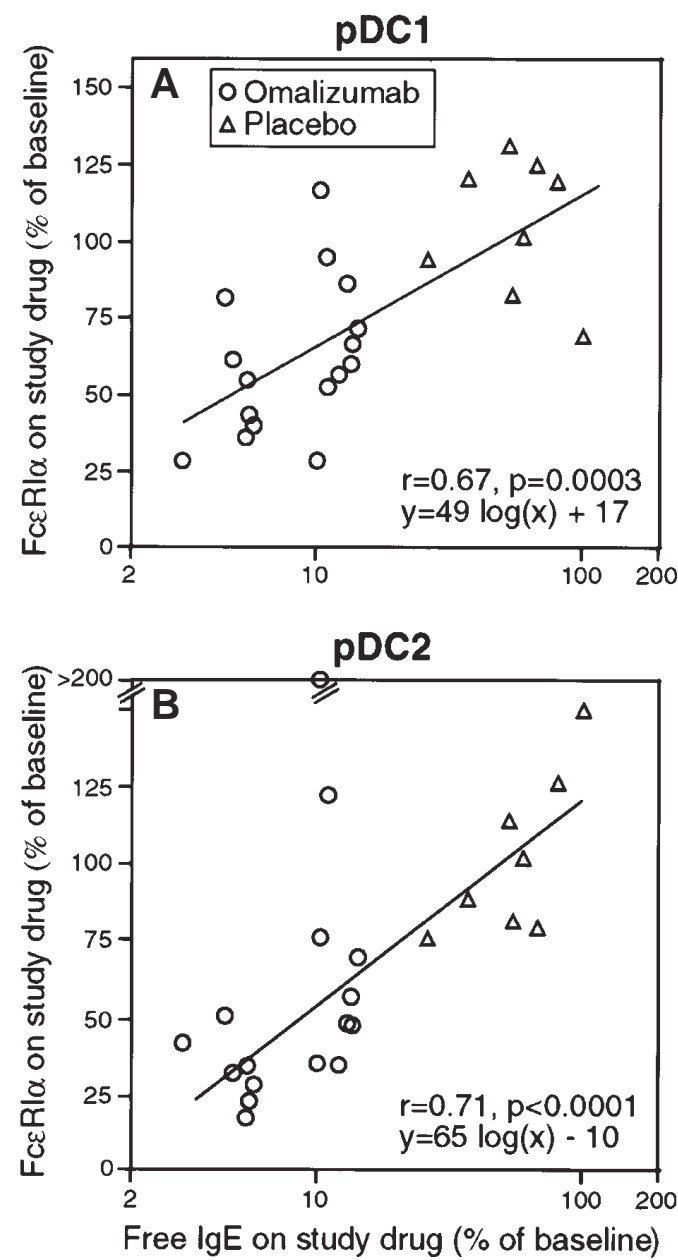

FIG 4. Correlation of DC FceRl $\alpha$ expression with serum IgE. For each subject, the fraction of $\operatorname{lgE}$ and FceRI during treatment with the study drug relative to the day 0 baseline value was determined as per the "Methods" section. The pDC1 and pDC2 values for FceRI were then plotted against that for serum IgE. Each symbol represents an individual subject. $R$ values and statistical significance were determined by using the Spearman rank correlation test. A line was fitted to these results by using linear regression and the equation describing that line noted on each graph.

izumab therapy similarly downregulates FceRI $\alpha$ expression by human DCs. The major clinical implication of our findings is that by downregulating DC FceRI expression and, consequently, inhibiting antigen focusing, anti-IgE might inhibit antigen presentation of allergen to $\mathrm{T}$ cells. This suggests the possibility that anti-IgE therapy might have the capacity to block both the sensitization and effector phases of the allergen-specific immune response.

Because of the limitations inherent in human research, the roles of specific molecules in disease pathogenesis are generally implicated from association rather than the more straightforward process of deleting a gene or gene product through genetic or pharmacologic means. Omalizumab provides a means to reduce free IgE levels in vivo and assess the immunologic consequences. The results in Fig 4 demonstrate that the decrease in FceRI $\alpha$ expression was
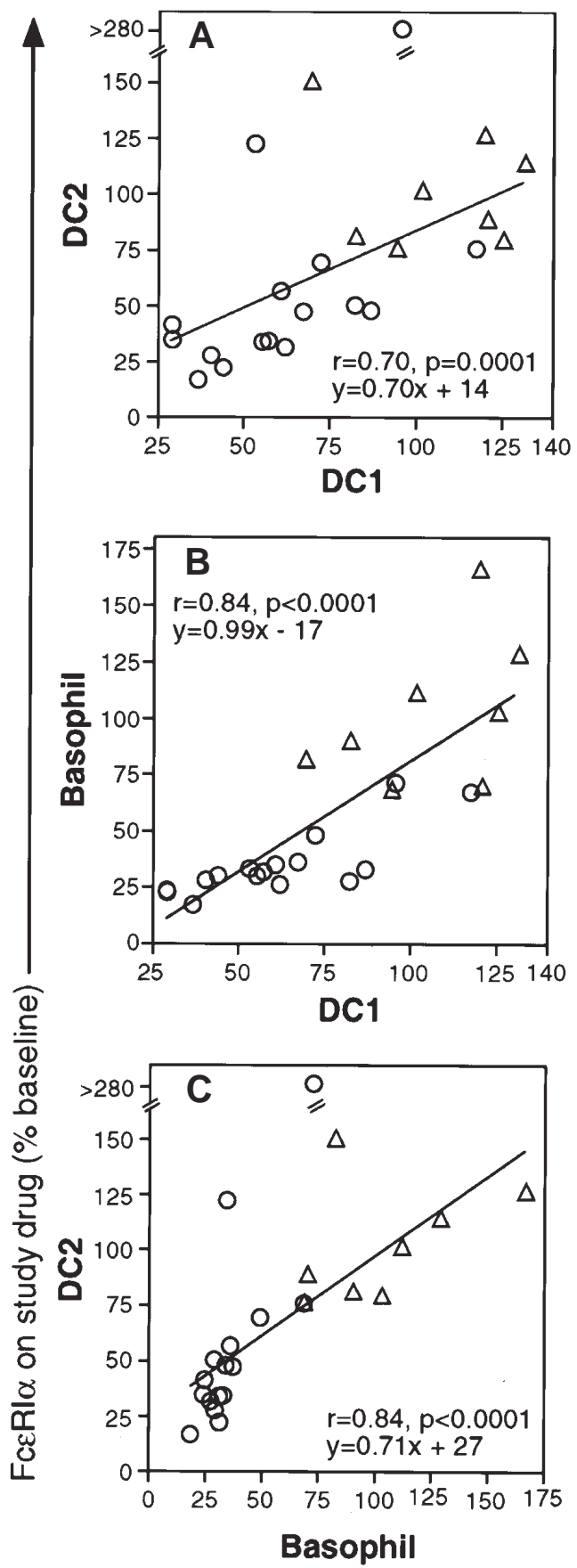

FceRl $\alpha$ on study drug ( $\%$ baseline)

OOmalizumab
$\triangle$ Placebo

FIG 5. Correlation of FceRI expression between the pDC1, pDC2, and basophil subsets. For each subject and cell subset, the fraction of FceRl expression during treatment with the study drug relative to the day 0 baseline was determined as per the "Methods" section. These values were then plotted against each other for the different pairs of cell subsets. Each symbol represents results for a unique subject. $R$ values and statistical significance were determined by using the Spearman rank correlation test. A line was fitted to these results using linear regression and the equation describing that line noted on each graph. 
highly correlated to the decrease in free IgE. This finding supports the concept that serum IgE levels directly influence DC FceRI expression. Furthermore, the magnitude of the reduction in FceRI expression was substantial (Figs 2 and 3 ). In sum, these data are consistent with the conclusion that $\mathrm{IgE}$ is a major factor regulating FceRI surface expression by human DCs in vivo. Given the results of previous in vitro studies, ${ }^{18}$ we believe our results reflect IgE stabilization of FceRI protein on the DC surface and not the result of increased transcription.

Antigen focusing by FceRI-bearing APCs has been proposed as a potential mechanism whereby $\operatorname{IgE}$ facilitates antigen presentation to allergen-specific $\mathrm{T}$ cells. Our results, demonstrating the downregulation of DC FceRI by omalizumab, suggest the possibility that anti-IgE, by inhibiting antigen focusing, might decrease allergen-specific T-cell activation. Such inhibition could potentially be operative at 2 major points of the T-cell immune response to allergen. First, the inhibition of the clonal expansion and differentiation of naive allergen-specific $T$ cells into $T_{H} 2$ cells would decrease the numbers of pathogenic allergenspecific $\mathrm{T}_{\mathrm{H}} 2$ cells. Second, the inhibition of allergen-specific $\mathrm{T}_{\mathrm{H}} 2$ cell activation would decrease the generation of inflammatory $\mathrm{T}_{\mathrm{H}} 2$ cytokines. If operative, such mechanisms would indicate that, in addition to its known effect on basophils and mast cells, anti-IgE therapy might have immunomodulatory effects on allergen-specific T cells.

The results we obtained for the pDC1 and pDC2 populations were largely parallel to those we found for basophils. For example, in Fig 5, the changes in FceRI expression were highly correlated among the basophil and pDC subsets. Moreover, in that same analysis, the slopes of the fitted lines between the basophil and pDC subsets were close to 1 , indicating that the magnitude of change in FceRI $\alpha$ expression was comparable in all 3 subsets. Finally, the kinetics of the FceRI decrease were similar in all 3 subsets. In sum, these data are consistent with the conclusion that FceRI is similarly regulated in the basophil, $\mathrm{pDC} 1$, and $\mathrm{pDC} 2$ populations.

A strength of this study is the use of pDCs, a wellcharacterized and accessible source of DCs $5,17,19$ that are well suited to serial sampling during an 8-week clinical drug trial.

To our knowledge, the downregulation of DC expression of FceRI by omalizumab has not been reported. However, a previous report examined the absolute numbers of pDCs in subjects with seasonal allergic rhinitis treated concurrently with omalizumab and allergen immunotherapy. ${ }^{20}$ This study found that the number of pDC1 was decreased in the omalizumab group relative to the placebo group, but this observation was limited to the grass pollen season and was not seen in the birch pollen season. Our study was performed out of the ragweed pollen season, did not measure the absolute numbers of pDCs in peripheral blood, and did not use allergen immunotherapy, and therefore a direct comparison of results is not possible. Both studies demonstrate that omalizumab treatment is associated with DC changes that might have immunotherapeutic consequences.
Specific DC subsets have different capacities to prime naive $\mathrm{T}$ cells toward a $\mathrm{T}_{\mathrm{H}} 1, \mathrm{~T}_{\mathrm{H}} 2$, or regulatory $\mathrm{T}$-cell phenotype. ${ }^{7,8,21}$ However, the relationship of specific DC subsets, their expression of FceRI, and the pathogenesis of allergic diseases is unclear and is the subject of active investigation. ${ }^{2,22-24}$ Thus the clinical consequences of downregulating FceRI on both the DC1 and DC2 subsets is an important area for future investigation.

In summary, there are several important implications of the research observations reported in this article. First, our findings support the concept that serum IgE concentration is a major determinant of FceRI surface expression by pDCs. Second, the action of omalizumab on pDCs underscores the potential for anti-IgE therapy to downregulate FceRI expression on a wide range of DCs and do so at an early stage of development before their trafficking into tissue and differentiation into mature DCs. Finally, the therapeutic downregulation of FceRI represents a unique molecular target whereby both the sensitization and effector phases of the allergen-specific immune response could be inhibited.

We thank Dr Mark VanRaden (NIAID) for statistical consultation and Bryan Sandlund (Genentech) for free IgE determinations.

\section{REFERENCES}

1. Prussin C, Metcalfe DD. 4. IgE, mast cells, basophils, and eosinophils. J Allergy Clin Immunol 2003;111(suppl):S486-94.

2. Novak N, Kraft S, Bieber T. Unraveling the mission of FceRI on antigenpresenting cells. J Allergy Clin Immunol 2003;111:38-44.

3. Maurer D, Fiebiger E, Reininger B, Ebner C, Petzelbauer P, Shi GP, et al. Fc $\varepsilon$ receptor I on dendritic cells delivers IgE-bound multivalent antigens into a cathepsin S-dependent pathway of MHC class II presentation. J Immunol 1998;161:2731-9.

4. Larche M, Haselden BM, Oldfield WL, Shirley K, North J, Meng Q, et al. Mechanisms of $\mathrm{T}$ cell peptide epitope-dependent late asthmatic reactions. Int Arch Allergy Immunol 2001;124:272-5.

5. Shortman K, Liu YJ. Mouse and human dendritic cell subtypes. Nat Rev Immunol 2002;2:151-61.

6. Kadowaki N, Ho S, Antonenko S, Malefyt RW, Kastelein RA, Bazan F, et al. Subsets of human dendritic cell precursors express different tolllike receptors and respond to different microbial antigens. J Exp Med 2001;194:863-9.

7. Rissoan MC, Soumelis V, Kadowaki N, Grouard G, Briere F, de Waal Malefyt R, et al. Reciprocal control of T helper cell and dendritic cell differentiation. Science 1999;283:1183-6.

8. Boonstra A, Asselin-Paturel C, Gilliet M, Crain C, Trinchieri G, Liu YJ, et al. Flexibility of mouse classical and plasmacytoid-derived dendritic cells in directing T helper type 1 and 2 cell development: dependency on antigen dose and differential toll-like receptor ligation. J Exp Med 2003;197:101-9.

9. Casale TB. Experience with monoclonal antibodies in allergic mediated disease: seasonal allergic rhinitis. J Allergy Clin Immunol 2001;108 (suppl):S84-8.

10. Boushey HA Jr. Experiences with monoclonal antibody therapy for allergic asthma. J Allergy Clin Immunol 2001;108(suppl):S77-83.

11. MacGlashan DW Jr, Bochner BS, Adelman DC, Jardieu PM, Togias A, McKenzie-White J, et al. Down-regulation of $\mathrm{Fc}(\varepsilon) \mathrm{RI}$ expression on human basophils during in vivo treatment of atopic patients with anti-IgE antibody. J Immunol 1997;158:1438-45.

12. Saini SS, MacGlashan D. How IgE upregulates the allergic response. Curr Opin Immunol 2002;14:694-7.

13. Casale TB, Bernstein IL, Busse WW, LaForce CF, Tinkelman DG, Stoltz $\mathrm{RR}$, et al. Use of an anti-IgE humanized monoclonal antibody in ragweed-induced allergic rhinitis. J Allergy Clin Immunol 1997;100:110-21.

14. Foster B, Schwartz LB, Devouassoux G, Metcalfe DD, Prussin C. Char- 
acterization of mast-cell tryptase-expressing peripheral blood cells as basophils. J Allergy Clin Immunol 2002;109:287-93.

15. Foster B, Prussin C. Detection of intracellular cytokines by flow cytometry. In: Coligan JE, Kruisbeek AM, Margulies DH, Shevach EM, Strober $\mathrm{W}$, editors. Current protocols in immunology. Hoboken (NJ): Wiley; 2003. p. 6.24.1-6.24.16.

16. Boesel KM, Griffith DT, Prussin C, Foster B, Lin H, Casale TB. Rapid reduction of basophil FcR1 expression by omalizumab. J Allergy Clin Immunol 2003;111(suppl):S264.

17. Dzionek A, Fuchs A, Schmidt P, Cremer S, Zysk M, Miltenyi S, et al. BDCA-2, BDCA-3, and BDCA-4: three markers for distinct subsets of dendritic cells in human peripheral blood. J Immunol 2000;165: 6037-46.

18. Borkowski TA, Jouvin MH, Lin SY, Kinet JP. Minimal requirements for IgE-mediated regulation of surface Fc $\varepsilon$ RI. J Immunol 2001;167:1290-6.

19. Dzionek A, Inagaki Y, Okawa K, Nagafune J, Rock JJ, Sohma Y, et al Plasmacytoid dendritic cells: from specific surface markers to specific cellular functions(1). Hum Immunol 2002;63:1133-48.
20. Feuchtinger T, Bartz H, von Berg A, Riedinger F, Brauburger J, Stenglein $\mathrm{S}$, et al. Treatment with omalizumab normalizes the number of myeloid dendritic cells during the grass pollen season. J Allergy Clin Immunol 2003;111:428-30.

21. Akbari O, DeKruyff RH, Umetsu DT. Pulmonary dendritic cells producing IL-10 mediate tolerance induced by respiratory exposure to antigen. Nat Immunol 2001;2:725-31.

22. Uchida Y, Kurasawa K, Nakajima H, Nakagawa N, Tanabe E, Sueishi M, et al. Increase of dendritic cells of type 2 (DC2) by altered response to IL-4 in atopic patients. J Allergy Clin Immunol 2001;108:1005-11.

23. Holloway JA, Holgate ST, Semper AE. Expression of the high-affinity IgE receptor on peripheral blood dendritic cells: differential binding of IgE in atopic asthma. J Allergy Clin Immunol 2001;107:1009-18.

24. Matsuda H, Suda T, Hashizume H, Yokomura K, Asada K, Suzuki K, et al. Alteration of balance between myeloid dendritic cells and plasmacytoid dendritic cells in peripheral blood of patients with asthma. Am J Respir Crit Care Med 2002;166:1050-4.

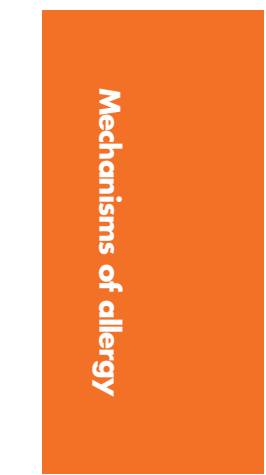

